\title{
Licitações públicas sustentáveis no Brasil: princípios e expectativas
}

\section{Public bidding sustainable at Brazil: principles and expectations}

\author{
Francisco Renê Fernandes Feitosa ${ }^{a}$ \\ Francilda Alcântara Mendes ${ }^{\mathrm{b}}$
}

\begin{abstract}
a Servidor técnico-administrativo da Universidade Federal do Cariri (UFCA). Especialista em Direito Administrativo e Gestão Pública pela Universidade Regional do Cariri (URCA). Possui graduação em Ciências Econômicas pela Universidade Regional do Cariri (URCA), cursando Direito na Universidade Regional do Cariri (URCA)

E-mail: reneffeitosa@gmail.com
\end{abstract}

${ }^{\text {b}}$ Doutoranda em Educação Brasileira pela UFC. Mestra em Desenvolvimento Regional Sustentável pela Universidade Federal do Ceará - UFC (2014). Bacharel em Direito pela Universidade Regional do Cariri (2010). Especialista em Direito Processual Civil pela Universidade Regional do Cariri (2011). Servidora Pública na Universidade Federal do Cariri UFCA. Advogada inscrita na Ordem dos Advogados do Brasil - CE e Professora do curso de Direito da Faculdade Leão Sampaio. É coordenadora do Laboratório Interdisciplinar de Estudos de Desenvolvimento e Sustentabilidade da Faculdade Leão Sampaio, membro do Laboratório de Estudos Avançados em Desenvolvimento Regional do Semiárido - LEADERS da Universidade Federal do Cariri e do Grupo da Linha de Pesquisa em História da Educação Comparada desenvolvida no âmbito do Doutorado em Educação Brasileira da Universidade Federal do Ceará. Desenvolve pesquisas com foco em Educação, Desenvolvimento Sustentável e Direito.

E-mail: francilda.mendes@ufca.edu.br

Recebido em: 16/09/2016 I Aceito em: 02/12/2016 


\section{RESUMO}

A inserção do tema da sustentabilidade na Lei 8.666/93 - assunto não apenas atual mas também necessário para que seus benefícios possam ser efetivados para toda a sociedade - é uma inovação legal promovida pela redação conferida ao art. 3o, caput, da Lei oㅜ 8.666, de 21 de junho de 1993, pela Lei oㅜ 12.349, de 15 de dezembro de 2010. Isso altera significativamente o quadro jurídico e operacional das licitações públicas brasileiras, tornando obrigatório todos os entes da Federação a promoverem licitações públicas sustentáveis. Esse tipo de contrato é influenciado por parâmetros de consumo menos agressivos ao meio ambiente, ou seja, consegue integrar critérios ambientais e técnicos de acordo com a atual ciência, praticando um preço razoável. Diante disso, esta pesquisa tem como objetivo averiguar o contexto histórico-social e a importância da inclusão do tema sustentabilidade na Lei de Licitações Públicas e pesquisar autores e obras que tratam da temática, além de avaliar a relação dos processos licitatórios com a sustentabilidade, fazendo um apanhado dos possíveis avanços econômicos e socioambientais que a inclusão da sustentabilidade na Lei de Licitações trouxe à Administração Pública. A metodologia qualitativa, por meio do levantamento bibliográfico de autores e obras que abordam a discussão proposta e a análise da evolução da legislação específica, indicaram que a inclusão da sustentabilidade na lei de licitações é relevante na medida em que incentiva a proteção ao meio ambiente embora a mera alteração legislativa não tenha o condão de transformar as compras públicas brasileiras.

Palavras-chave: Licitações. Sustentabilidade. Compras Públicas Sustentáveis

\section{ABSTRACT}

The insertion of theme of inclusion of sustainability in Law 8,666 / 93 - a subject not only current but also necessary so that yours benefits can be made effective for the whole society - is a legal innovation promoted by the wording given to art. 3, caput, of Law No. 8,666, of June 21, 1993, by Law No. 12,349 of 15 December 2010. This alters significantly the legal and operational framework of Brazilian public bids, mandating all Federation entities to promote sustainable public bids. This type of contract is influenced by consumption parameters less harmful to the environment, that is, it gets to integrate environmental and technical criteria according to current science, practicing a reasonable price. Thus, this research aims to investigate the historical and social context and the importance of including the issue of sustainability in the Public Bids Law and search authors and works that deal with the subject, and to evaluate the relationship of bidding processes to sustainability, making an overview of the possible economic and environmental advances that the inclusion of sustainability in the Bidding Law brought to the Public Administration. The qualitative methodology through the literature of authors and works that address to the proposed discussion and analysis of the evolution of specific legislation indicated that the inclusion of sustainability in the bidding law is relevant as it encourages the protection of the environment, though the mere legislative change does not have the power to transform Brazilian public procurement.

Keywords: Bids. Sustainability. Sustainable Public Procurement. 


\section{INTRODUÇÃO}

A presente pesquisa permeia o campo do Direito Administrativo, por tratar da questão da sustentabilidade nos processos licitatórios. A partir desse contexto, surge a hipótese de que a inclusão do paradigma sustentável nas aquisições do setor público implica em avanços sociais significativos, os quais serão discutidos no desenvolvimento deste estudo.

Assim, a problemática da pesquisa envolve as raízes da inclusão da prerrogativa da sustentabilidade nas licitações públicas, bem como suas consequências gerais, discutidas por autores das áreas correlatas ao tema. Entende-se que seja de suma importância discutir e entender essa questão proposta, sobretudo no que tange às razões que levaram o Legislativo a inclui-lo no ordenamento jurídico brasileiro.

O objetivo geral desta pesquisa é investigar o contexto histórico-social e a relevância da inclusão do tema da sustentabilidade na Lei de Licitações Públicas (8.666/93). Já os objetivos específicos são: pesquisar autores e obras que abordem o tema da sustentabilidade; analisar a relação do Direito Administrativo, em especial dos processos licitatórios, com o paradigma da sustentabilidade e levantar os possíveis avanços econômicos e socioambientais que a inclusão da sustentabilidade na Lei de Licitações acarretou para a Administração Pública brasileira.

A relevância desta pesquisa está alicerçada no fato de que a sustentabilidade é tema de destaque na maioria dos debates da sociedade contemporânea. Isso porque o paradigma sustentável envolve a preocupação com ações que garantam maior qualidade de vida para as gerações atuais e, sobretudo, as futuras.

Para a realização desta pesquisa foram utilizadas pesquisas em livros e sítios da internet, incluindo consultas a leis que tratam do tema proposto, levando em consideração a natureza e o escopo do problema de pesquisa.

\section{METODOLOGIA}

A pesquisa é descritiva-exploratória e doutrinária, descreve as características de determinado fenômeno e estabelece relações entre variáveis e é voltada para discutir o que é o Direito, o que é a lei, em uma área particular (OLIVEIRA, 2013). 
Segundo a mesma autora, "a pesquisa doutrinária concentra-se no próprio Direito como um conjunto interno e autossustentado de princípios, que podem ser acessados através da leitura de decisões judiciais e de estatutos". Dessa forma, a pesquisa doutrinária se aprofunda na natureza de uma lei.

Assim, esta pesquisa se utiliza da legislação relevante (fontes primárias), apoiada em modelos teóricos (fontes secundárias) direcionados a encontrar, entender e aplicar regras e princípios na solução de um problema legal num caso concreto, qual seja a questão da sustentabilidade nas licitações publicas brasileiras.

Para tanto, será utilizada a metodologia qualitativa, por meio do levantamento bibliográfico de autores e obras que tratam desse tema, incluindo também a análise da evolução da legislação específica.

O trabalho identifica e analisa o material baseado em fatos, bem como identifica o contexto legal em que surgem as questões fatuais do tema em questão, esclarecendo as fontes para a investigação dos fatos relevantes e determinando quando os fatos são necessários, através da análise das questões jurídicas apresentadas por documentos e teorias para, por fim, apresentar os resultados da pesquisa de forma clara, útil e confiável (STOTT apud OLIVEIRA, 1999).

\section{A evolução do conceito de sustentabilidade no mundo}

Em 1987, a noção de desenvolvimento sustentável é apresentada ao mundo no Relatório Brundtland, também conhecido como "Nosso Futuro Comum", preparado pela Comissão Mundial sobre Meio Ambiente e Desenvolvimento da Organização das Nações Unidas (ONU).

Esse relatório nos traz o conceito de desenvolvimento sustentável como "o desenvolvimento que satisfaz às necessidades presentes, sem comprometer a capacidade das gerações futuras de suprir suas próprias necessidades". Ele propõe, assim, um conjunto de medidas voltadas para o desenvolvimento sustentável (VALENTE, 2011).

Durante o ano de 1992 foi elaborada, como resultado do encontro da Conferência Mundial sobre Meio Ambiente e Desenvolvimento no Rio de Janeiro, a Agenda 21. Esse documento se trata de um plano de ações a ser adotado em níveis global, nacional e local, por organizações do sistema das Nações Unidas, governos 
e pela sociedade civil, em todas as áreas em que a ação humana possa impactar o meio ambiente (idem, 2011).

A Agenda 21 deve ser entendida como a consolidação de um amplo programa de sustentabilidade ambiental, reafirmando e ampliando as recomendações do Relatório Brundtland, bem como promovendo um padrão de desenvolvimento atualizado, que leva em conta indicadores de eficiência econômica, além da preservação da sustentabilidade ambiental (idem,2011).

O poder de compra dos Estados nacionais, o qual é extremamente expressivo, possui processos de seletividade de bens e serviços, atualmente, já com critérios de sustentabilidade ambiental incorporados, como é o caso do Brasil.

Sabe-se que vários países já passaram a utilizar como mecanismo de fomento iniciativas voltadas para a produção de bens e serviços sustentáveis. Destarte, os Estados começam a tornar suas ações altamente relevantes do ponto de vista do incentivo ao mercado, no sentido de adotar critérios sustentáveis na fabricação de produtos. Há dados consolidados, há 12 (doze) anos atrás, que demonstram que, já naquela ocasião, havia um forte potencial de indução contido nas compras públicas.

Em 1999, é estabelecida a Agenda Ambiental na Administração Pública (A3P), sob a coordenação do Ministério do Meio Ambiente, tendo como objetivo estimular os gestores públicos a incorporar princípios e critérios de gestão ambiental, tendo como consequência a economia de recursos naturais, bem como a redução de gastos institucionais por meio do uso racional dos bens públicos e da gestão dos resíduos.

O caráter orientador da A3P deve-se ao fato de que esse programa de gestão administrativa sustentável não possui natureza impositiva, regulatória, mas, tão somente, de indução às boas práticas de gestão sustentável.

No ano de 2010 há o surgimento dos novos modelos de compras públicas sustentáveis, pois o Ministério do Planejamento, Orçamento e Gestão, por meio de sua Secretaria de Logística e Tecnologia da Informação adota a Instrução Normativa no 1 , de 19 de janeiro de 2010, estabelecendo critérios de sustentabilidade ambiental na aquisição de bens, contratação de serviços ou obras na Administração Pública Federal.

Esse foi o primeiro marco regulatório que adotou critérios de sustentabilidade ambiental na esfera do governo federal, no que se refere a licitações sustentáveis. 
Dessa forma, ficou estabelecida, a partir desse momento, a imposição da promoção de compras públicas sustentáveis (idem, 2011).

\section{Conjuntura atual e sustentabilidade}

A preocupação ambiental está estimulando a Administração Pública a procurar novos paradigmas de aquisição de bens para atender suas necessidades e inúmeras iniciativas agregadoras de critérios de sustentabilidade ambiental já foram adotadas, visando reduzir impactos ambientais e gerais.

No âmbito da Administração Pública é fundamental que os princípios sustentáveis estejam presentes, pois os mesmos têm compromisso principalmente com a eficiência no emprego dos recursos públicos, contribuindo para uma gestão mais justa.

Dessa forma, abordar a inserção do tema da sustentabilidade na Lei 8.666/93 é uma discussão não apenas atual, mas também necessária para que os benefícios do paradigma sustentável possam, de fato, ser efetivados para toda a sociedade.

Além disso, a crescente participação dos entes governamentais no que tange à participação no mercado, levando a grandes aquisições de produtos e uma importante utilização de serviços particulares urge que valores alicerçados na sustentabilidade estejam presentes nessas transações, a fim de que o respeito à eficiência dos serviços públicos seja preservada.

Logo, a preocupação com a sustentabilidade é um tema que vem desbravando o ramo do Direito e conquistando cada vez mais espaço, no intuito de se adaptar à realidade presente, em que o meio ambiente se encontra altamente degradado pela ação humana em suas práticas de consumo geralmente inconscientes e inconsequentes. $E$ não só isto, mas também enfatizando perspectivas sociais, econômicas e políticas mais conscientes, ao considerar a sustentabilidade uma possível solução para a questão da degradação ambiental atual.

Para Veiga (2010), o processo de avaliação, mensuração e monitoramento da sustentabilidade tende a exigir necessariamente a utilização de indicadores, ao passo que estatisticamente não é recomendado fundir em um mesmo índice apenas duas de suas três dimensões: 
A resiliência dos ecossistemas certamente poderá ser expressa por indicadores não monetários relativos, por exemplo, às emissões de carbono, à biodiversidade e à segurança hídrica. Mas o grau de tal resiliência ecossistêmica não dirá muito sobre a sustentabilidade se não puder ser cotejado a dois outros. Primeiro, o desempenho econômico não poderá continuar a ser avaliado com o velho viés produtivista, e sim por medida da renda familiar disponível. Segundo, será necessária uma medida de qualidade de vida (ou bem-estar) que incorpore as evidências científicas desse novo ramo que é a economia da felicidade.

A inovação legal promovida pela redação conferida ao art. $3^{\circ}$, caput, da Lei $n^{\circ}$ 8.666, de 21 de junho de 1993, pela Lei no 12.349, de 15 de dezembro de 2010, altera o quadro jurídico e operacional das licitações públicas brasileiras, tornando obrigatório todos os entes da Federação a promoverem licitações públicas sustentáveis.

Essa recente intervenção jurídica acompanha a tendência das últimas décadas no sentido da promoção do desenvolvimento uma consciência sustentável, tanto no setor público, como no setor privado, uma vez que a população em geral tende a acompanhar regras governamentais vigentes.

Assim, é nesse debate que se espera trazer à tona a compreensão do contexto histórico-social da inclusão do tema da sustentabilidade na Lei de Licitações Públicas e a sua relevância em âmbito geral para a sociedade.

A relação que existe entre a sociedade e o Direito tem um duplo sentido de adaptação, pois de um lado o ordenamento jurídico é elaborado no sentido de um processo de adaptação social e, para tanto, deve ajustar-se às condições do meio; por outro lado, o Direito estabelecido exige a necessidade de adaptação do povo ao seu comportamento, aos novos padrões de convivência.

Assim, o Direito deve ser uma "expressão da vontade social", ou seja, a legislação deve exclusivamente assimilar aqueles valores positivos que a sociedade vivencia e exalta. Desse modo, em regra o Direito não faz correspondência a necessidades individuais, mas a uma carência surgida da coletividade, exigindo, portanto, uma "equação social" (NADER, 2011).

A partir daí nos questionamos: qual tem sido a vontade social mais urgente? Quais valores se tornaram essenciais à sociedade contemporânea? Nessa seara sabe-se que durante as últimas décadas a humanidade degradou constantemente os ecossistemas do planeta, como nunca antes, em consequência das atividades econômicas desenvolvidas em âmbito global, com a hegemonia da Revolução Industrial. 
A preocupação social com tal questão se deu a partir da década 1960, quando as discussões ambientais tomaram maior amplitude e é nessa conjuntura que a humanidade hoje se depara com um dos maiores desafios para o século XXI em que mesmo se colocou, qual seja a tentativa de redefinir as relações mantidas com a natureza de forma a conseguir reconfigurar o estado de sua condição ambiental, já muito degradado atualmente (Camargo, 2012).

Nesse contexto, surge o conceito de sustentabilidade, na segunda metade da década de 1980, trazendo consigo uma possível solução viável, talvez única, para a questão dos conflitos ambientais contemporâneos. Esse novo conceito, mesmo sem consenso e ainda com nuances polêmicas, se encontra, cada vez mais, no cerne dos discursos oficiais, sendo introduzindo no campo político por ser de amplo interesse público (Camargo, 2012).

Stahel (1998) apud Camargo (2012), numa divagação polêmica, reflete se de fato há a possibilidade de haver um desenvolvimento sustentável dentro do sistema capitalista de mercado, já que o que se percebe nas entrelinhas é a existência de um despertar do "desenvolvimento capitalista sustentável", o que dificulta mudanças efetivas na sociedade, não passando de um conceito incorporado pelo sistema vigente.

Os progressos tecnocientíficos das últimas décadas e a ampliação da longevidade das populações, bem como o aumento quantitativo de habitantes, forçaram a economia a voltar-se para potencializar a expansão de seus mercados no sentido de elevar os níveis de produção, tendo uma maior necessidade de matériasprimas e de recursos naturais (Valente, 2011).

Esse cenário gerou péssimas consequências, sobretudo no tocante às pressões sobre o meio ambiente, que passaram a ser significantes com a busca de novas fontes de recursos e a degradação ambiental resultante do despejo de resíduos na natureza. Em contrapartida, tem-se percebido a formação de uma consciência de preservação ambiental e de desenvolvimento sustentável nestas últimas décadas (idem, 2011).

Para elucidar o conceito de desenvolvimento sustentável, nos traz Chacon (2007) que esse processo deve considerar de forma satisfatória a distribuição social justa de resultados inerentes ao progresso científico-tecnológico aliada ao respeito ao meio ambiente, o que ultrapassa meros aspectos econômicos. 
Ainda no entendimento da autora, o Brasil, na condição de país de terceiro mundo, tem um "novo dever de casa" diante do desenvolvimento sustentável. Isso significa que, muitas vezes surgido como imposição dos organismos internacionais de financiamento, a sustentabilidade passou a constar primeiro como base obrigatória para os planos de governo, sendo posteriormente assimilada por outras instâncias da sociedade.

Segundo Sachs (1994), precursor das discussões que construíram o arcabouço para a ideia de sustentabilidade, o ecodesenvolvimento significa um desenvolvimento socioeconômico equitativo, o qual opta por um processo de desenvolvimento que considere o meio ambiente sensível às oscilações econômicas. Reconhecê-lo como base de qualquer sistema vital ou econômico é uma de suas premissas.

O autor nos traz as dimensões do ecodesenvolvimento, as quais são complementares e inseparáveis, a saber:

a) Sustentabilidade social: promove a justiça social para que se amenizem as diferenças entre ricos e pobres, principalmente redistribuindo rendas e bens;

b) Sustentabilidade econômica: realoca eficientemente recursos macrossociais, inclusive entre nações.

c) Sustentabilidade ecológica: potencializa o uso dos recursos de forma criativa e responsável, limitando o uso de recursos não renováveis e promovendo o uso de recursos renováveis. Além disso, busca diminuir a poluição e aumentar a reciclagem; fomenta as pesquisas para a descoberta de tecnologias limpas; normatiza, institucionaliza e instrumentaliza a proteção ao meio ambiente.

d) Sustentabilidade espacial: Distribui melhor as atividades econômicas e humanas através de um equilíbrio entre as zonas rural e urbana.

e) Sustentabilidade cultural: promove o desenvolvimento local, levando-se em conta os saberes locais.

Inserido também nesse contexto, as compras governamentais podem gerar alto impacto e concorrer positivamente para que os agentes econômicos passem a investir na produção de bens e serviços ambientalmente sustentáveis. Isso levou o governo federal brasileiro a investir, com maior ênfase, na normatização das compras públicas sustentáveis (Valente, 2011).

Moura (2013) reforça esta ideia de que o consumo governamental de bens e serviços é relevante para a economia interna ao nos lembrar que cerca de $8 \%$ a $25 \%$ 
do Produto Interno Bruto (PIB) de um país refere-se ao dispêndio do governo. No Brasil, conforme afirma Biderman et al (2008) estima-se que as compras públicas, nos diversos níveis de governo, consigam movimentar cerca de $10 \%$ do PIB.

É interessante ressaltar que o volume de recursos que o setor público movimenta, consumindo um grande porte de produtos e serviços disponíveis no mercado, o coloca numa posição privilegiada, pois cria condições para o surgimento de economias de escala, as quais alavancam as margens de lucros dos produtores e reduzem seus riscos (MOURA, 2013).

As compras do Governo podem, também, estimular a competição e a inovação das indústrias na direção desejada, bem como possibilitar, com o seu poder de compra, a "liderança pelo exemplo", com a utilização de ferramentas de promoção de políticas públicas voltadas à sustentabilidade. O papel indutor do Estado não se restringe à criação de regulações, impostos e incentivos, estando na situação de um dos consumidores mais ativos do mercado econômico (idem, 2013).

\section{Licitação pública e seus conceitos}

Atuando de forma divergente dos particulares, a Administração Pública não deve estar livre à prática de atos e atividades, pois há o dever, em seus processos, de agir conforme a lei, regra expressamente exposta no artigo $5^{\circ}$, II, da Constituição Federal.

É dizer que a Gestão Pública liga-se ao regime jurídico-administrativo e, por isso, atende aos princípios da legalidade e impessoalidade, dentre outros, ligados de forma direta ao processo de licitar, o qual objetiva a celebração de contratos (FURTADO, 2010).

Em regra, o administrador público deve licitar, no entanto há casos em que a licitação será arbitrária. As hipóteses em que o administrador estará autorizado a contratar diretamente, sem que tenha que proceder à realização de licitação, são exceções e se encontram expressamente mencionadas na Lei nำ 8.666/93.

Caso não cumpra-se o procedimento licitatório, sem que haja fundamento para essa contratação direta, haverá implicação o cometimento de crime, nos termo do art. 89 da Lei n 8.666/93 (idem, 2010).

A Constituição Federal, em seu art. 22, inciso XXVII, com a redação dada pela Emenda Constitucional $\mathrm{n} ¹ 9$, confere à União competência privativa para legislar 
sobre normas gerais de licitações e contratos administrativos, nos seguintes termos (idem,2010):

Art.22. Compete privativamente à União legislar sobre:

XXVII - normas gerais de licitação e contratação, em todas as modalidades, para as administrações públicas diretas, autárquicas e fundacionais da União, Estados, Distrito Federal e Municípios, obedecido o disposto no art. $37, \mathrm{XXI}$, e para as empresas públicas e sociedades de economia mista, nos termos do art. $173, \S 1^{\circ}$, III;

Conforme Mello (2011), o Poder Público, ao se diferenciar dos particulares no que tange aos limites em adquirir, alienar, locar bens e contratar a execução de obras ou serviços, possibilita a seleção de propostas mais vantajosas às suas conveniências, ao contrário dos particulares que o fazem livremente.

Logo, segundo o mesmo autor, a licitação é "um certame que as entidades governamentais devem promover e no qual abrem disputa entre os interessados em com ela travar determinadas relações de conteúdo patrimonial (...)". Para tal, a competição licitatória deve ser isonômica, ou seja, deve haver justiça mediante a igualdade de direitos a todos, utilizando, em regra, os mesmos critérios. Faz-se necessário expor os conceitos dos doutrinadores do Direito quanto às licitações. José dos Santos Carvalho Filho define licitação como o:

[...] procedimento administrativo vinculado por meio do qual os entes da Administração Pública e aqueles por ela controlados selecionam a melhor proposta entre as oferecidas pelos vários interessados, com dois objetivos a celebração do contrato, ou a obtenção do melhor trabalho técnico, artístico ou científico. (CARVALHO FILHO, 2009)

A definição de Hely Lopes Meirelles é mais voltada à eficiência e moralidade na atuação da Administração Pública:

[...] procedimento administrativo mediante o qual a Administração Pública seleciona a proposta mais vantajosa para o contrato de seu interesse. Como procedimento, desenvolve-se através de uma sucessão ordenada de atos vinculantes para a Administração e para os licitantes, o que propicia igual oportunidade a todos os interessados e atua como fator de eficiência e moralidade nos negócios administrativos. (MEIRELLES, 2004, p.266)

Considerando a definição de Di Pietro (2011) quanto à licitação pública, podese definir:

[...] a licitação como o procedimento administrativo pelo qual um ente público, no exercício da função administrativa, abre a todos os interessados, que se sujeitem às condições fixadas no instrumento convocatório, a possibilidade de formularem propostas dentre as quais selecionará e aceitará a mais conveniente para a celebração de contratos. 
Com relação ao imperativo de o Poder Público realizar procedimentos licitatórios, esse se encontra no artigo 37, inciso XXI, da Constituição Federal, o qual afirma que:

\begin{abstract}
Ressalvados os casos especificados na legislação, as obras, serviços, compras e alienações serão contratados mediante processo de licitação pública que assegure igualdade de condições a todos os concorrentes, com cláusulas que estabeleçam obrigações de pagamento, mantidas as condições efetivas da proposta, nos termos da lei, o qual somente permitirá as exigências de qualificação técnica e econômica indispensáveis à garantia do cumprimento das obrigações.
\end{abstract}

Furtado (2010) aponta que não realizar licitação implica em severa punição, dada pelo artigo 89 da Lei 8.666/93, seção Dos Crimes e das Penas, em que dispõe:

Art. 89. Dispensar ou inexigir licitação fora das hipóteses previstas em lei, ou deixar de observar as formalidades pertinentes à dispensa ou à inexigibilidade:

Pena- detenção, de 3 (três) a 5 (cinco) anos, e multa.

Parágrafo único. $\mathrm{Na}$ mesma pena incorre aquele que, tendo comprovadamente concorrido para a consumação da ilegalidade, beneficiou-se da dispensa ou inexigibilidade ilegal, para celebrar contrato com o Poder Público.

A licitação sustentável busca a associação de critérios ambientais, sociais e econômicos na tomada de decisão do processo licitatório. Tais critérios, para serem avaliados, devem levar em consideração a real necessidade de aquisição do produto ou serviço, a disponibilidade de estudos e tecnologias sustentáveis, o ciclo de vida e o descarte. A Constituição Federal estabeleceu, além disso, que a ordem econômica deve assegurar a existência digna conforme os ditames da justiça social e o princípio da defesa do meio ambiente.

\title{
4 Licitação sustentável: conceitos, vantagens e incentivos
}

Bim (2011) afirma que a licitação sustentável - também conhecida como ecoaquisição, licitação ecológica, verde ou ambiental - se define como aquela influenciada por parâmetros de consumo que agridam menos o meio ambiente.

Significa dizer que é o tipo de licitação que consegue integrar critérios ambientais e técnicos de acordo com a atual ciência, praticando um preço plausível, 
sendo que:

É um esforço governamental com base jurídica, propiciado não apenas por ela, mas principalmente pela consciência institucional do consumo sustentável (educação ambiental) para adquirir bens, serviços e obras com reduzido impacto ambiental em comparação com os outros que servem à mesma finalidade. Tal comparação poderá, por exemplo, considerar o material bruto, a produção, o fabrico, o empacotamento, a distribuição, o reuso, a operação, a manutenção ou a disposição/eliminação do produto ou serviço (BIM, 2011).

A Cartilha da Agenda Ambiental na Administração Pública (2009) nos traz o conceito de compras sustentáveis, as quais:

Consistem naquelas em que se tomam atitudes para que o uso dos recursos materiais seja o mais eficiente possível. Isso envolve integrar os aspectos ambientais em todos os estágios do processo de compra, de evitar compras desnecessárias a identificar produtos mais sustentáveis que cumpram as especificações de uso requeridas. Logo, não se trata de priorizar produtos apenas devido a seu aspecto ambiental, mas sim considerar seriamente tal aspecto juntamente com os tradicionais critérios de especificações técnicas e preço.

Ou seja, a Administração Pública não deve atentar somente para aspectos técnicos ou mercadológicos em seus processos de aquisição, mas também se conscientizar da conjuntura atual para que promova compras mais sustentáveis, contribuindo para a preservação e conservação dos recursos da natureza, tão essenciais à existência da vida no planeta.

Para Moura (2013) o conceito de Compras Públicas Sustentáveis está diretamente relacionado com o desenvolvimento sustentável:

Em linhas gerais, compras públicas sustentáveis (CPS) são aquelas que incorporam critérios de sustentabilidade nos processos licitatórios; ou seja, são consistentes com os princípios abarcados pelo desenvolvimento sustentável - um conceito complexo que busca promover uma sociedade mais justa e equitativa para as gerações atuais e futuras -, desenvolvendose nos limites (ou na capacidade de suporte) do meio ambiente.

Nesse sentido, o artigo 170, VI, da Constituição Federal, determina que a ordem econômica observe "a defesa do meio ambiente, inclusive mediante tratamento diferenciado conforme o impacto ambiental dos produtos e serviços e de seus processos de elaboração e prestação".

A adoção de compras públicas sustentáveis implica no estabelecimento de políticas estatais para atingir padrões ambientais e sociais através de metas, sem a necessidade de alocar recursos extras em seu orçamento. 
Isso deixa o mercado livre para a busca de formas eficientes de atendimento aos objetivos que o governo pretende. Assim, o Estado não absorve novos custos para atingir a realidade almejada nos quesitos ambientais e sociais, abrindo mão de medidas de controle administrativo, uma vez que o mercado está trabalhando nesse sentido (BRASIL E LILEI , 2011, apud MOURA, 2013).

Moura (2013) explica que Compras Públicas Sustentáveis (CPS) ou Licitações Públicas Sustentáveis ou, ainda, licitações positivas, para o governo brasileiro são aquisições orientadas por critérios de sustentabilidade. Já aquelas compras que envolvem apenas critérios ambientais são uma subcategoria das licitações sustentáveis, conhecidas como compras verdes, compras ambientalmente amigáveis ou ecoaquisições.

Para a autora, o incentivo à adoção de padrões sustentáveis de produção e consumo deve partir de um conjunto formal de leis e de outros instrumentos normativos que o regulamentem. Tal regulamentação deve se relacionar ao processo produtivo sustentável e à responsabilidade pós-consumo, minimizando a geração de resíduos e reintegrando materiais utilizados durante o ciclo produtivo, através da reciclagem e/ou logística reversa. Assim, o incentivo às CPS pode se dar por:

a) criação ou supressão de tributos específicos;

b) oferecimento de subsídios;

c) estabelecimento de um portfólio de produtos a serem incluídos prioritariamente nas licitações públicas;

d) desenvolvimento de ferramentas de apoio (manuais de orientação e bancos de dados com exemplos de editais e produtos sustentáveis).

Moura (2013) nos apresenta, ainda, outra forma de incentivos às CPs e o cuidado que o administrador público deve ter ao lidar com o princípio da isonomia no que se refere às licitações:

Os critérios de sustentabilidade também podem ser estabelecidos de acordo com rótulos/selos ambientais e certificações já disponíveis no mercado. Não se pode exigir que os fornecedores possuam determinado selo ou rótulo ambiental a priori, pois isto colocaria uma barreira no princípio da isonomia entre os competidores, não havendo respaldo legal para este procedimento. Mas se pode estabelecer, por exemplo, que todos os produtos ofertados no certame cumpram as normas estabelecidas em determinado rótulo. Os produtos que não tenham o rótulo podem apresentar qualquer outro meio de prova adequado, por exemplo, uma especificação técnica do fabricante, que demonstre que o produto cumpre com os critérios. 
Quanto às vantagens das compras públicas sustentáveis, Moura (2013) cita as seguintes:

a) ajuda os governos a atingirem metas relacionadas às mudanças climáticas, à gestão de resíduos sólidos e à gestão de recursos hídricos;

b) o aumento da compra de madeira certificada, a redução da geração de resíduos e, também, do desperdício no uso da água;

c) os produtos sustentáveis são geralmente mais duráveis, consumindo menos energia.

d) incentiva o surgimento de novos mercados e empregos "verdes", área que tende a ganhar mais espaço no cenário internacional nos próximos anos;

e) alavanca melhorias ao garantir condições de trabalho adequadas aos operários que trabalham em obras públicas ou promovendo novas oportunidades de trabalho para grupos marginalizados.

\section{Ordenamento jurídico relacionado às licitações sustentáveis}

A ordem econômica e financeira brasileira adota o princípio da defesa do meio ambiente com o desenvolvimento sustentável sendo enunciado pelo artigo $170 \mathrm{da}$ Constituição Federal de 1988. A Carta Magna também consagra expressamente a relevância do meio ambiente ecologicamente equilibrado em seu artigo 225, que diz:

\footnotetext{
Todos têm direito ao meio ambiente ecologicamente equilibrado, bem de uso comum do povo e essencial à sadia qualidade de vida, impondo-se ao Poder Público e à coletividade o dever de defendê-lo e preservá-lo para as presentes e futuras gerações.
}

A Lei de Política Nacional do Meio Ambiente $n^{\circ}$ 6.938, de 31 de agosto de 1981, mesmo antecedendo a Constituição Federal, proporcionou o surgimento do Direito Ambiental Brasileiro como uma ciência autônoma. A referida lei tem por objetivo a preservação, melhoria e recuperação da qualidade ambiental, visando assegurar, no país, condições ao desenvolvimento socioeconômico, aos interesses da segurança nacional e à proteção da dignidade da vida humana. Em suma, essa lei vislumbra a compatibilização do desenvolvimento econômico-social com a preservação da qualidade do meio ambiente e do equilíbrio ecológico. 
Com a Lei $n^{\circ}$ 7.347, de 24 de julho de 1985, o Estado disciplina a Ação Civil Pública de responsabilidade por danos causados ao meio ambiente e a Lei de Crimes Ambientais, $\mathrm{n}^{\circ}$ 9.605, de 12 de fevereiro de 1998, a qual dispõe sobre as sanções penais e administrativas derivadas de condutas e atividades lesivas ao meio ambiente e outras providências.

Assim, não há vedação à licitação sustentável pelo ordenamento jurídico, pois não há afronta a dispositivo legal. Ao contrário, chega-se à conclusão de que a Constituição Federal, a Política Nacional do Meio Ambiente e a própria Lei de licitações possuem, na proteção do meio ambiente, um dever do Poder Público.

O Congresso Nacional, no ano de 2010, ao deliberar sobre o projeto de lei da conversão de medida provisória, instituiu o marco legal das licitações sustentáveis no âmbito da Administração Pública brasileira:

\begin{abstract}
Essa importante inovação legal, promovida pela redação conferida ao art. 3으, caput, da Lei oㅡ 8.666, de 21 de junho de 1993, pela Lei oㅜ 12.349, de 15 de dezembro de 2010, modifica radicalmente o quadro jurídico e operacional das licitações públicas no Brasil, obrigando todos os entes da Federação a promoverem licitações públicas sustentáveis. (VALENTE, 2011)
\end{abstract}

No entanto, segundo Valente (2011) é preciso considerar que, mesmo antes da alteração do caput do art. $3^{\circ}$ da Lei $n^{\circ} 8.666$, de 1993, já havia um marco jurídico implícito para fundamentação de licitações sustentáveis na Constituição Federal, especialmente de seus arts. 23, VI, 170, VI, e 225 em combinação com o art. 37, $\mathrm{XXI}$.

O objetivo do Governo, como fica claro nos trechos da Exposição de Motivos da Medida Provisória no 495, de 2010, com a modificação da Lei Geral de Licitações, foi a de acrescentar às licitações públicas uma função de indução do desenvolvimento nacional, pelo poder de compra governamental. Dessa forma, a Administração Pública brasileira, desde 15 de dezembro de 2010, está obrigada a promover licitações sustentáveis. Valente (2011) nos explica em quê isso implica:

\begin{abstract}
Nesse novo contexto legal, as contratações de serviços, de obras e de compras por parte do setor público exige que sejam introduzidos, nos respectivos editais licitatórios, quando da definição do objeto dos certames, critérios ou especificações que tornem compatíveis as licitações com parâmetros de sustentabilidade ambiental, sem frustrar a competitividade ou promover discriminações entre potenciais interessados na participação em processos licitatórios.
\end{abstract}

Espera-se que com a inserção de requisitos de sustentabilidade na prática das licitações públicas ocorra uma importante promoção no tocante às relações 
entre o Estado e o mercado produtor de bens e serviços, ao induzir ações voltadas para a defesa e a preservação do meio ambiente, incorrendo em padrões que visem ao atendimento das necessidades do Estado, considerando também a redução dos abusos ao meio ambiente e à própria sociedade (VALENTE, 2011).

Assim, a preocupação ambiental está estimulando o setor público a procurar novos paradigmas de aquisição de bens para atender suas necessidades e, dessa forma, inúmeras iniciativas agregadoras de critérios de sustentabilidade ambiental foram adotadas pela Administração Pública, visando reduzir impactos ambientais, das quais podemos destacar as seguintes aquisições:

a) lâmpadas de alto rendimento, com menor teor de mercúrio.

b) cabos e fios de alta eficiência elétrica e baixo teor de chumbo e policloreto de vinila - PVC.

c) papel reciclado.

d) envelopes fabricados com papel reciclado.

e) produtos ou equipamentos que não contenham substâncias degradadoras da camada de ozônio.

f) veículos movidos a álcool ("Frota Verde").

g) madeira certificada.

h) "computadores verdes", que não contenham mercúrio, chumbo, cromo hexavalente, cádmio, lifenilpolibramados e éteres difenil - polibromados.

Com o desenvolvimento do paradigma da sustentabilidade e o seu reconhecimento por parte do governo brasileiro, entende-se que há, em regra, um avanço fatual com esta inovação legal, para toda a sociedade, haja vista a importância das compras do Estado no montante de aquisições no mercado em geral, dentre outros fatores relevantes. No entanto, alguns pontos específicos devem, ainda, evoluir nesse processo.

\section{Eficácia da inclusão da sustentabilidade na norma jurídica: 0 desafio da aplicabilidade prática do conceito}

Sabe-se que a dogmática jurídica cumpre três funções primordiais: política, ideológica e pedagógica, ou seja, o Direito é o grande pedagogo que informa a sociedade o que é certo e o que é errado, ou melhor, o que é licito e o que não é lícito para que se possa haver o mínimo de harmonia em sociedade. 
Estas normas, porém, não são neutras, mas fruto de um processo de escolha política em que os nossos representantes elegem os comportamentos permitidos comumente a partir dos valores defendidos pelas classes dominantes. Senão vejamos:

\begin{abstract}
A dogmática jurídica preocupa-se com possibilitar uma decisão e orientar a ação, estando ligada a conceitos fixados, ou seja, partindo de premissas estabelecidas. Essas premissas ou dogmas estabelecidos (emanados da autoridade competente) são, a priori, inquestionáveis. No entanto, conformadas as hipóteses e o rito estatuídos na norma constitucional ou legal incidente, podem ser modificados de tal forma a se ajustarem a uma nova realidade. A dogmática, assim, limita a ação do jurista condicionando sua operação aos preceitos legais estabelecidos na norma jurídica, direcionando a conduta humana a seguir o regulamento posto e por ele se limitar, desaconselhando, sob pena de sanção, o comportamento contra legem. Mas não se limita "a copiar e repetir a norma que the é imposta, apenas depende da existência prévia desta norma para interpretar sua própria vinculação (ADEODATO, 2012).
\end{abstract}

Desta forma, a inserção da sustentabilidade na dogmática do Direito Administrativo nos impele a refletir em que medida a positivação deste valor pode de fato gerar alterações significativas nas licitações públicas. Pois, não adianta que o conceito seja incorporado à norma se não forem adotadas medidas práticas que garantam a sua aplicabilidade, seja por meio de políticas públicas efetivas, seja por meio da capacitação dos servidores públicos para compreender a temática sustentável. Caso isto não ocorra, apesar de todos os aspectos benéficos já abordados até aqui a inclusão da sustentabilidade na Lei de Licitações pode tornarse mera falácia.

Seria ingênuo pensarmos que é possível que a inserção do tema na lei já garanta o desenvolvimento sustentável, já que isto não será possível enquanto juristas e servidores públicos não estejam apropriados do tema a ponto de saber lidar com o mesmo em suas múltiplas dimensões e não apenas na seara ambiental. Além da legislação fazem-se indispensáveis a existência e a boa aplicação de políticas públicas aliadas a iniciativas de conscientização da população para a questão, bem como uma gradual adaptação das empresas fornecedoras de matérias-primas ao governo.

Embora o conceito de sustentabilidade esteja sendo amplamente difundido pelas grandes empresas multinacionais e pelos Governos percebe-se que o mesmo não é exercido de forma satisfatória ou verdadeira. Há uma falsa ilusão de que produtos sustentáveis conseguem evitar devastações ambientais, aumento de 
desigualdades sociais, perdas de culturas, dentre tantas outras implicações. $\mathrm{Na}$ verdade ainda temos o emprego do desenvolvimento como sinônimo de crescimento econômico: o progresso deve vir a qualquer custo e não podemos afirmar que os gestores públicos estão realmente comprometidos com estratégias sustentáveis (NEDEL et al, 2015)

Outro desafio que pode ser apontado para que se verifique a eficácia da inclusão da sustentabilidade em nossa legislação é a ausência de indicadores precisos que atestem a existência do desenvolvimento sustentável, pois sendo este um conceito multidimensional ainda não foram definidos critérios universais que possam servir de base para que verifiquemos ações sustentáveis.

Sobre a temática importante a contribuição de Bellen (2005) ao afirmar que:

\begin{abstract}
a dificuldade de fornecer e desenvolver indicadores para os aspectos humanos do desenvolvimento sustentável persiste. Dentro de uma observação mais detalhada existe uma mistura entre o bem-estar dos indivíduos (como os aspectos relativos à saúde, educação, ausência de pobreza) e questões relacionadas ao capital social que está longe de ter uma definição universal, incluindo aspectos como leis, confiança, estabilidade, acesso a informações, instituições adequadas e ausência de corrupção. (...) Esses indicadores são difíceis de ser capturados em um ou alguns poucos indicadores quantitativos. ( BELLEN, 2005, p. 75)
\end{abstract}

Apesar de todos estes percalços para a real efetividade da sustentabilidade no âmbito do Direito Administrativo brasileiro, em especial nos processos licitatórios, faz-se relevante ressaltar que a iniciativa do Legislativo brasileiro em garantir lisura, respeito ao meio ambiente e transparência nas licitações é um importante passo no processo de evolução do arcabouço legal do país na busca do desenvolvimento sustentável.

\title{
7 Considerações Finais
}

Quando se trata da inclusão da prática da sustentabilidade na Lei de Licitações 8.666/93, considerando sê-la atual e necessária para a evolução social e econômica, há de se considerar que os conceitos sustentáveis vêm sendo introduzidos no ramo do Direito e conquistando espaço gradualmente, no intuito de se adaptar à crítica realidade atual.

As compras do Governo, as quais têm o poder de estimular a competição e a inovação do mercado na direção desejada, possuem, no papel indutor do Estado, relativa capacidade de atenuar ou, atém mesmo, reverter a realidade atual. No 
entanto, mesmo com o advento do conceito de sustentabilidade aplicado ao campo governamental, dado pelas inovações introduzidas pelo Poder Legislativo Brasileiro na ordem jurídica, faz-se relevante considerarmos que torna-se complicado a conclusão de que as licitações irão tornar-se completamente sustentáveis de fato a partir da alteração da legislação atual.

Esta afirmação se baseia na realidade atual que mostra que ainda não existem critérios objetivos bem definidos e consolidados que permitam definir o que é e o que não é sustentável no caso prático. É dizer que se faz urgente, primordialmente, uma mudança de paradigmas e conceitos no tocante ao consumo e ao consumismo, inclusive na esfera pública.

Analisando sob uma perspectiva crítica do Direito, podemos concluir que a mera edição de leis não tem o poder de gerar as melhorias sociais almejadas. Além da legislação serão indispensáveis políticas públicas e atitudes educacionais para que os cidadãos possam se comprometer com a sustentabilidade, assim como a legislação vigente manifesta em seu texto. Também é primordial que as políticas públicas consigam promover situações favoráveis às empresas licitantes, de modo a não emperrar o processo de compras sustentáveis, promovendo acordos rentáveis e atrativos à iniciativa privada.

Deve-se considerar que as mudanças sociais esperadas através das compras públicas sustentáveis somente serão alcançadas pelo esforço conjunto entre sociedade civil e Estado, no sentido de aplicar de forma otimizada as diretrizes pensadas para o futuro do país. Sem dúvida, estamos diante de uma prática que deve ser expandida no sentido de preservar a humanidade e promover a qualidade de vida de forma ampla.

\section{REFERÊNCIAS}

ADEODATO, João Maurício. Ética e retórica. São Paulo: Ed. Saraiva, 2012.

BELLEN, Hans Michael Van. Indicadores de sustentabilidade: uma análise comparativa. São Paulo: Ed. FGV, 2006.

BIDERMAN, Rachel et al. (Orgs.). Guia de compras públicas sustentáveis: uso do poder de compra do governo para a promoção do desenvolvimento sustentável. 2. ed. Rio de Janeiro: Editora FGV, 2008. 
BIM, Eduardo Fortunato. Considerações sobre a juridicidade e os limites da licitação sustentável. In: SANTOS, Murillo Giordan; BARKI, Teresa Villac Pinheiro (Coord.). Licitações e contratações públicas sustentáveis. $1^{a}$ ed. 1 reimpr. Belo Horizonte: Forum, 2011.

CAMARGO, Ana Luiza de Brasil. Desenvolvimento Sustentável: dimensões e desafios. 6 ed. Campinas: Papirus, 2012.

CHACON, Salgueiro, Suely. O sertanejo e o caminho: políticas públicas, modernidade e sustentabilidade no semi-árido. Fortaleza: Banco do Nordeste do Brasil, 2007.

Cartilha da Agenda Ambiental na Administração Pública, 2009. Disponível em: < http://www.cabo.pe.gov.br/pners/CONTE\%C3\%9ADO\%20DIGITAL/\%C3\%93RG\%C3 \%83OS\%20E\%20ENTIDADES\%20P\%C3\%9ABLICAS/A3P/CARTILHA\%20\%20AGENDA\%20AMBIENT\%20NA\%20ADM\%20P\%C3\%9ABLICA.pdf> Acesso em 12 set. 2016.

CARVALHO FILHO, José dos Santos. Manual de Direito Administrativo. 21. ed. Rio de Janeiro: Lumen Juris, 2009.

DI PIETRO, Maria Sylvia Zanella. Direito Administrativo. 24 ed. São Paulo: Atlas, 2011.

FURTADO, Lucas Rocha. Curso de Licitações e contratos administrativos, 3 ed. Belo Horizonte: Fórum, 2010.

MEIRELLES, Hely Lopes. Direito Administrativo Brasileiro. 29. ed. São Paulo: Malheiros, 2004.

MELLO, Celso Antônio Bandeira de. Curso de Direito Administrativo, 29 ed. Malheiros Editores, 2011.

MOURA, Adriana Maria Magalhães de, Boletim regional, urbano e ambiental /Instituto de Pesquisa Econômica Aplicada: Ipea, 2013: Disponível em: $<$ http://ipea.gov.br/agencia/images/stories/PDFs/boletim_regional/131127_boletimreg ional7_cap3.pdf>. Acesso em 13 set. 2016. 
NADER, Paulo. Introdução ao estudo do Direito , Rio de Janeiro: Forense, 2011.

OLIVEIRA, Luci. Metodologia do Trabalho de Conclusão De Curso (TCC), 2013. Disponível em: <http://docplayer.com.br/1114890-Metodologia-do-trabalho-deconclusao-de-curso-tcc.html> Acesso em 16 set. 2016.

NEDEL, N. K.; GREGORI, I. C. S. ; HUNDERTMARCH, B. ; SANTIAGO, L. S. Desenvolvimento Sustentável: uma falácia imposta pela ótica mercadológica internacional em detrimento das próprias facetas da sustentabilidade. in: VII SPI, 2015, Florianópolis, 2015.

SACHS, I. Estratégias de transição para o século XXI. In: BURSZTYN, M. (Org.). Para pensar o desenvolvimento sustentável. 2. ed. São Paulo: Brasiliense, 1994.

VALENTE, Manoel Adam Lacayo, Marco Legal das Licitações e Compras Sustentáveis na Administração Pública, 2011: Disponível em:

<http://www.governoemrede.sp.gov.br/ead/lictsustentavelbr/Midiateca/Artigos/marco legal_valente.pdf>. Acesso em 10 set. 2016.

VEIGA, José Eli da. Indicadores de sustentabilidade, 2010: Disponível em < http://www.scielo.br/scielo.php?script=sci_arttext\&pid=S0103-40142010000100006>. Acesso em 6 set. 2016. 